\title{
LOS LÍMITES DE LA PRIVACIDAD
}

\section{Óscar ZAVALA GAMBOA*}

Sin lugar a dudas, el derecho a la privacidad históricamente ligado a la protección de datos personales se encuentra frente a grandes predicamentos, particularmente ante al desarrollo tecnológico e industrial que se está viviendo. Basta observar los efectos de la denominada Industria 4.0 o Cuarta Revolución Industrial, para advertir que los escenarios son cada vez más complejos, y la privacidad en ámbitos como redes sociales, operaciones financieras, prestación de servicios (nacional o internacional), entre muchos otros más, encuentran obstáculos que hasta hace algunos años hubieran sido impensables, y que permiten cuestionar si verdaderamente el marco jurídico se encuentra listo para afrontar estas novedades.

Así, el desarrollo tecnológico vinculado con lo que algunos consideran como el derecho humano a la comunicación aparece como uno de los grandes temas de la agenda internacional contemporánea, y como ejemplo tenemos a la Unión Internacional de Telecomunicaciones, organismo especializado de la Organización de las Naciones Unidas que promueve el análisis, y sobre todo la conscientización de la importancia que tiene este tema en las sociedades y el interés - tanto del sector público como el privado- por que se discutan y posicionen avances y retos en esta materia.

Por lo anterior, la obra que se reseña del destacado sociólogo norteamericano Amitai Etzioni es una lectura obligada para los interesados en el derecho a la privacidad y la protección de datos personales; sin embargo, considero que tiene una especial relevancia entre los abogados estudiosos de estos temas, ya que la visión sociológica permite identificar nuevas aristas

Licenciado y maestro en derecho por la Facultad de Derecho, UNAM. Actualmente es secretario de acuerdos y ponencia en el Instituto Nacional de Transparencia, Acceso a la Información y Protección de Datos Personales y profesor en la Facultad de Derecho (UNAM) y en la Escuela Libre de Derecho. Correo: ozavalagamboa@derecho.unam.mx. 
en temas complejos que han sido poco abordados desde el ámbito jurídico, y que muestran un panorama en el que el derecho parece desfasado frente a situaciones actuales, cada vez más presentes de lo que se pueden imaginar.

En ese sentido, parece oportuno retomar las palabras del profesor José Ramón Agustina, importante jurista que tiene la encomienda de prologar la obra en comento. El profesor Agustina comienza señalando que en la obra de Etzioni se analizan los problemas de la privacidad desde una "perspectiva ortodoxa". Se entiende por ésta a un cambio en el paradigma que resulta "perturbador", cuestión que resume muy bien la visión que se plasma en esta obra, donde se cuestionan desde los elementos más bási- cos de la noción de privacidad, hasta su aplicación en problemáticas muy - específicas, y que podrían situarse en lo que Ronald Dworkin denominaría como "casos difíciles".

La obra de Etzioni parte de una premisa fundamental: identificar y aceptar que la noción de privacidad se encuentra en graves predicamentos y en un asedio inigualable. Por ello, el autor se compromete a demostrar que los defensores radicales de la privacidad no sólo han incurrido en excesos retóricos, sino que en su consideración esos excesos han tenido consecuencias significativas y perjudiciales, que son detalladas y analizadas a lo largo de todo el libro. Para tal efecto, el autor no se limita a analizar la cuestión conceptual, sino que va más allá, al plantear escenarios complejos en los que busca sostener la tesis central.

La selección de casos es más que atinada, y permite al lector, confrontar lo que históricamente se ha conocido como derecho a la privacidad — tal vez desde los postulados de Samuel Warren y Louis Brandeis-, con problemáticas actuales, como pruebas de VIH, actos relacionados con delitos sexuales, intervención de comunicaciones, sistemas biométricos y el uso de expedientes médicos, situaciones de actualidad y gran relevancia que llevan a cuestionar si realmente hay un derecho a la privacidad y cuáles deberían ser sus retos y sus limitaciones.

En ese sentido, el autor plantea que los verdaderos retos son identificar cómo puede servirse mejor el bien común en cuestión sin socavar innecesariamente la privacidad, cuáles son los perjuicios concretos que conlleva privilegiar la privacidad, y qué recursos específicos de política pública pueden implementarse para minimizar la reducción de la privacidad que conllevaría el tratamiento de esos perjuicios. Por último, cuestiona cómo se deberían abordar las cuestiones morales, legales y sociales planteadas por los recursos sugeridos.

Como se observa, el profesor Etzioni, de entrada plantea las limitaciones propias de la privacidad como punto de partida; pero la gran ventaja de 
esta obra es que el autor sí propone un método de estudio para determinar si la relación entre privacidad y el bien común (entendido como publicidad de la información) es desequilibrada, y entonces qué puede hacerse para corregir ese desequilibrio.

Finalmente, el autor busca construir la idea de un concepto contemporáneo de privacidad, en el que se establezcan sus características, pero también sus limitaciones, lo que permita identificar cuáles son sus ámbitos de aplicación y los casos en los que deberá ceder ante el bien común referido.

Sin lugar a dudas, la obra de Amitai Etzioni resulta novedosa y actual (a pesar del tiempo que ha pasado desde que fue escrita y luego traducida), por lo que invito al lector a adentrarse en esta postura diferente, que indudablemente le permitirá cuestionarse sobre los alcances y limitaciones del derecho a la privacidad.

Para concluir, se retomarán las palabras del jurista Miguel Carbonell, y que parecen especialmente importantes, a propósito de la obra que se reseña:

Uno de los signos de las democracias contemporáneas es la separación entre actividades públicas y privadas de los individuos. Si esa separación no existiera se correría el riesgo de caer en alguno de los dos extremos siguientes: o bien se pulverizarían varios de los derechos fundamentales más importantes dentro de la lógica del Estado constitucional (como el derecho a la inviolabilidad del domicilio, la libertad de creencias, la libertad ideológica, la libertad de procreación, etcétera), o bien — en el otro extremo- se diluirían varios de los sistemas de control que actualmente existen para verificar la actuación de las autoridades (las reglas de comportamiento que rigen en el ámbito público son distintas de las que existen en el ámbito privado, y para los funcionarios públicos se crea todo un sistema de mecanismos de verificación que solamente se puede mantener para el caso en que la distinción entre público y privado sea clara) (Carbonell, 2006: 450).

\section{Ficha BIbLIOGRÁFICA DEL LIBRO RESEÑAdo}

Etzioni, Amitai, 2012, Los límites de la privacidad, Montevideo-Buenos Aires, Editorial B. de F.

\section{OtRA Fuente}

Carbonell, Miguel, 2006, Los derechos fundamentales en México, México, Porrúa. 